punctatus Sturm.

spinipes Gyllh.

spinula Zett.

punctatus Er.

edentatus Sahlb.

fulvescens Guilleb.

a. punctatissimus Steph.

tarsalis Riehl.

punctatissimus Er.

v. intermedius Thoms.

Zu dieser Art dürfte vielleicht auch gehören puncticollis Reitt., welche Art nach der Originalbeschreibung abgerundete Halsschildhinterecken hat und sich von punctatus nur dadurch unterscheidet, daß der Halsschild nur wenig schwächer punktiert ist als die Flügeldecken. Exemplare aus dem Kaukasus könnten da Aufklärung bringen.

Unbekannt sind mir noch: secundus Guilleb., andalusicus Dieck und septentrionalis Thoms. Weiteres Untersuchungsmaterial, namentlich aus Spanien und Frankreich einerseits und vom Norden Europas andererseits, wäre mir sehr erwünscht.

\title{
Eine neue Varietät des Colon angulare Er.
}

\author{
Von Sanitätsrat Dr. A. Fleischer in Brünn.
}

\section{Colon angulare var. Ganglbaueri $\mathrm{m}$.}

Vom Habitus und Größe der Normalform des angulare; speziell ist auch beim Männchen die äußere Apicalecke an den Hinterschenkeln deutlich zähnchenartig vorspringend. Der Halsschild ist vor dem Hinterrande ein wenig abgeflacht. Die Punktierung des Halsschildes und der Flügeldecken ist, im Gegensatz zur Stammform, sehr fein und dicht. Das normale angulare hat bekanntlich eine sehr grobe und wenig dichte Punktierung.

Von Herrn Direktor Gangelbauer wurden bei Crissolo (Italien) vier Exemplare und von Herrn Hofrat Dr. Skalitzky bei Golling (Steiermark) ein Exemplar gefunden. 


\section{$2 \mathrm{BHL}$ Biodiversity Heritage Library}

Fleischer, Antonin. 1907. "Eine neue Varietät des Colon angulare ER." Wiener entomologische Zeitung 26, 268. https://doi.org/10.5962/bhl.part.8888.

View This Item Online: https://www.biodiversitylibrary.org/item/45299

DOI: https://doi.org/10.5962/bhl.part.8888

Permalink: https://www.biodiversitylibrary.org/partpdf/8888

\section{Holding Institution}

Smithsonian Libraries

\section{Sponsored by}

Smithsonian

\section{Copyright \& Reuse}

Copyright Status: NOT_IN_COPYRIGHT

This document was created from content at the Biodiversity Heritage Library, the world's largest open access digital library for biodiversity literature and archives. Visit BHL at https://www.biodiversitylibrary.org. 